\title{
Fish oil attenuates adrenergic overactivity without altering glucose metabolism during an oral glucose load in haemodialysis patients
}

\author{
Jacques Delarue $^{1 *}$, Marie-Paule Guillodo ${ }^{2}$, Sophie Guillerm ${ }^{1}$, Anthony Elbaz ${ }^{3}$, Yanic Marty ${ }^{3}$ \\ and Jacques Clèdes ${ }^{2}$ \\ ${ }^{1}$ Laboratoire Régional de Nutrition Humaine \& EA-948 'Oxylipides', CHU Cavale Blanche, F-29200 Brest, France \\ ${ }^{2}$ Association pour l'Aide aux Urémiques chroniques de Bretagne, F-29200 Brest, France \\ ${ }^{3}$ UMR CNRS 6321, Université de Bretagne Occidentale, F-29200 Brest, France
}

(Received 21 May 2007 - Revised 2 August 2007 - Accepted 13 August 2007 - First published online 1 November 2007)

Haemodialysis patients display an increased cardiac mortality, which may be partly related to increased sympathoadrenal activity and insulin resistance. Fish oil decreases adrenal activation induced by mental stress and has an insulin sensitizing effect in healthy subjects. Whole-body glucose metabolism after oral glucose was studied in eight haemodialysis patients before and after a 3-week oral fish oil supplementation (i.e. EPA + DHA at $1 \cdot 8 \mathrm{~g} / \mathrm{d}$ ). Plasma glucose fluxes were traced by using $\left[6,6-{ }^{2} \mathrm{H}_{2}\right]$ glucose infusion. Substrate oxidation was determined by using indirect calorimetry. Each patient was studied in the basal state and over the $6 \mathrm{~h}$ following absorption of a $1 \mathrm{~g} / \mathrm{kg}$ glucose load. Energy expenditure in response to glucose re-increased over the last $2 \mathrm{~h}$ of the experiment $(P<0.05)$, which coincided with an increase in plasma catecholamines, especially epinephrine $(P<0.05)$, strongly suggesting a sympathoadrenal overactivity. Fish oil supplementation blunted both re-increase in thermogenic response and concomitant increase in plasma epinephrine, but not in plasma norepinephrine, over the last $2 \mathrm{~h}$ of the experiment. Fish oil did not alter either whole-body glucose metabolism or substrate oxidation. These data show that in haemodialysis patients, fish oil attenuates adrenal overactivity induced by oral glucose but does not modulate whole-body glucose metabolism and insulin sensitivity.

n-3 Fatty acids: Stable isotopes: Energy metabolism: Nutrition: End-stage renal disease

A recent study showed that long-term haemodialysis (HD) patients consumed fish far below current American Heart Association recommendations ${ }^{1}$, which was associated with a decreased plasma and erythrocyte membrane content in long-chain $n$-3 PUFA. In addition, a multivariate analysis carried out in 216 dialysis patients showed that patients who reported fish intake had an approximately $50 \%$ lower risk of death at 1 year $^{2}$. Cardiac disease is the major cause of death in dialysis patients; approximately $20 \%$ of cardiac deaths are attributed to acute myocardial infarction ${ }^{3}$. Chronic renal failure is characterized by a generalized vasculopathy ${ }^{4}$. Increased sympathetic tone $\mathrm{e}^{5-8}$ and insulin resistance ${ }^{9}$ are, among a great variety, two risk factors that may contribute to the accelerated cardiovascular morbidity in patients undergoing HD for end-stage renal disease.

Long-chain $n$-3 PUFA, given as an oral fish oil supplementation, prevent the increase in sympathetic activity elicited by mental stress in healthy subjects ${ }^{10}$. Fish oil also reduces by $40 \%$ the insulinaemic response to oral glucose in healthy subjects without altering plasma glucose utilization, strongly suggesting an insulin-sensitizing effect ${ }^{11}$. Moreover, fish oil supplementation partially prevents dexamethasone-induced insulin resistance in healthy subjects ${ }^{12}$. Taken together, these data suggest that long-chain $n$ - 3 PUFA could be useful in HD patients with increased sympathetic tone and insulin resistance.

The study of metabolic response to an oral glucose load before and after fish oil supplementation allows quantification of effects of long-chain n-3 PUFA on both sympathetic activity and whole-body glucose metabolism. Indeed, thermogenic response, i.e. increase in energy expenditure (EE), following glucose absorption includes a facultative component due to sympathoadrenal activation ${ }^{13,14}$. Moreover, insulin sensitivity can be assessed from concomitant determinations of plasma glucose and insulin concentrations following oral glucose $\mathrm{e}^{15}$ and from determination of plasma glucose utilization by using stable isotope labelling of plasma glucose $\mathrm{e}^{11}$.

The present work aimed to study whether or not a 3-week dietary fish oil supplementation (EPA + DHA at $1.8 \mathrm{~g} / \mathrm{d}$ ) modulates sympathoadrenal activity and/or whole-body glucose metabolism during an oral glucose load in HD patients.

Abbreviations: CAPD, continuous ambulatory peritoneal dialysis; EE, energy expenditure; HD, haemodialysis; RaT, total rate of plasma glucose appearance; RdT, total rate of plasma glucose disappearance.

* Corresponding author: Professor Jacques Delarue, fax +332983478 82, email jacques.delarue@univ-brest.fr 


\section{Subjects and methods}

Subjects

Eight patients (six men, two women, 62 (SEM 7) years, 68.5 (SEM 3.7) $\mathrm{kg}$, BMI 24.7 (SEM 1.8) $\mathrm{kg} / \mathrm{m}^{2}$ ) undergoing HD for at least 6 months for end-stage renal disease were included. Aetiologies of end-stage renal disease were: polycystic disease of kidney (two), nephroangiosclerosis (one), tuberculosis (one), chronic interstitial nephropathy (one), chronic glomerulonephritis (one), post-traumatic nephropathy on unique kidney (one) and one of unknown cause. Mean duration of HD at day of inclusion in the study was: 7.5 (SEM 3) years $(n 8)$. No patient had personal or familial history of diabetes and/or obesity. None was taking any drug that could alter glucose metabolism or sympathetic activity.

Each subject had given written consent. The protocol was submitted and accepted by Ethical Committee of Brest.

\section{Protocol}

Patients were studied twice before and after a 3-week dietary supplementation with $6 \mathrm{~g} / \mathrm{d}$ of a fish oil containing $18 \%$ EPA and $12 \%$ DHA (Maxepa ${ }^{\circledR}$; Pierre Fabre, Castres, France), i.e. an intake of $1.8 \mathrm{~g} / \mathrm{d}$ of EPA + DHA. Fish oil was given as two caps three times per d. Its composition is reported in Table 1.

All tests were started at 07.00 hours after patients had experienced a $12 \mathrm{~h}$ overnight fast. The patients were weighted, voided if non-anuric, and were placed at rest in a bed and maintained in the supine position all over the experiment. An intravenous catheter was inserted into a superficial wrist vein for blood sampling. Another catheter was placed into a deep controlateral forearm vein for tracer infusion. A primed-constant infusion of $\mathrm{D}-\left[6,6-{ }^{2} \mathrm{H}_{2}\right]$ glucose was started $150 \mathrm{~min}$ before the oral load and maintained for $510 \mathrm{~min}$. The rate of tracer infusion was $70 \mu \mathrm{g} / \mathrm{kg}$ per min. All patients absorbed over $5 \mathrm{~min} 1 \mathrm{~g}$ glucose $/ \mathrm{kg}$ diluted into $300 \mathrm{ml}$ water

Table 1. Composition of Maxepa ${ }^{\circledR *}$

\begin{tabular}{lr}
\hline Fatty acids & \multicolumn{1}{c}{$\%$} \\
\hline $16: 0$ & 21.97 \\
$18: 0$ & $3 \cdot 15$ \\
$16: 1 n-7$ & $13 \cdot 30$ \\
$18: 1 n-9$ & $10 \cdot 55$ \\
$18: 1 n-7$ & 3.97 \\
$18: 2 n-6$ & 1.90 \\
$18: 2 n-4$ & $0 \cdot 41$ \\
$18: 3 n-3$ & $1 \cdot 26$ \\
$20: 1 n-9$ & $2 \cdot 01$ \\
$20: 1 n-7$ & $0 \cdot 18$ \\
$20: 2 n-6$ & $0 \cdot 14$ \\
$20: 3 n-6$ & $0 \cdot 11$ \\
$20: 4 n-6$ & $1 \cdot 14$ \\
$20: 4 n-3$ & 1.08 \\
$20: 5 n-3$ & 21.53 \\
$22: 1 n-11$ & 0.00 \\
$22: 4 n-6$ & 0.00 \\
$22: 5 n-6$ & 0.30 \\
$22: 5 n-3$ & 1.98 \\
$22: 6 n-3$ & $10 \cdot 69$ \\
Others & 4.30 \\
$\alpha-$ Tocopherol acetate (mg/g oil) & 1.75 \\
\hline
\end{tabular}

*Pierre Fabre, Castres, France (time $0 \mathrm{~min}$ ). Blood samples were sequentially obtained for determination of plasma glucose, insulin, metabolite concentrations and isotopic enrichment in ${ }^{2} \mathrm{H}$ of plasma glucose in the basal state and following glucose absorption. Plasma catecholamines were determined at times 180, 210, 240, 300 and $360 \mathrm{~min}$.

Indirect calorimetry was performed using a canopy (Deltatrac Metabolic Monitor II; Datex Omheda, Helsinki, Finland). The patients wore the canopy during $1 \mathrm{~h}$ prior to the oral load, during the $3 \mathrm{~h}$ following the load and during $30 \mathrm{~min}$ for each of the remaining $3 \mathrm{~h}$. Urine was collected at the end of the experiment only in non-anuric patients.

\section{Sampling procedures and analytical methods}

Blood samples were immediately spun at $4^{\circ} \mathrm{C}$. Plasma was aliquoted and frozen at $-80^{\circ} \mathrm{C}$ until time of assay. Urine samples were collected and frozen at $-20^{\circ} \mathrm{C}$ for further determination of urinary urea. Plasma samples $(1 \mathrm{ml})$ were extracted with $12 \mathrm{ml} \mathrm{CHCl}_{3}-\mathrm{MeOH}(2: 1, \mathrm{v} / \mathrm{v})$ according to the method described by Folch et al. ${ }^{16}$. The final lipid extract was stored at $-20^{\circ} \mathrm{C}$ after addition of $0.01 \%$ butylated hydroxytoluene (antioxidant). Neutral lipids were separated from lipid extract on a silicagel microcolumn (Kieselgel 60; 70-230 mesh; Merck; $10 \mathrm{ml} \mathrm{CHCl}_{3}-\mathrm{MeOH}$ (98:2, v/v)) according to Marty et al. ${ }^{17}$. TAG and NEFA were isolated by HPLC from the neutral lipid fraction as previously described by Soudant et al. ${ }^{18}$ on a diol column (OH-bound silica gel column, Lichrosorb Diol $5 \mu \mathrm{m}, 250 \times 4 \mathrm{~mm}$ i.d.; Merck) using a binary mobile phase (mixtures of hexane and isopropanol). TAG and NEFA fractions were analysed for fatty acid composition using GC, after transesterification with $\mathrm{MeOH}-\mathrm{BF}_{3}$ as previously described ${ }^{17}$. Fatty acid composition of fish oil was also analysed by the same method ${ }^{17}$.

Plasma glucose concentrations were measured using a YSI 2300 STAT Plus Glucose \& Lactate Analyzer (Ysi Life Sciences, Yellow Springs, USA). Plasma NEFA were determined by an enzymatic colorimetric method using a commercial kit (NEFA C; Wako Chemicals, Neuss, Germany). Plasma immunoreactive insulin concentrations were measured by RIA (INSIK5; CIS Bio International, Gif/Yvette, France). Plasma catecholamines were determined by HPLC.

The enrichments in ${ }^{2} \mathrm{H}$ were determined on the pentacetate derivative of glucose as previously described ${ }^{11}$.

\section{Calculations}

Protein oxidation was estimated from urinary urea excretion corrected for variation of body urea pool ${ }^{19}$. In anuric patients, protein oxidation was estimated from variation of body urea pool as previously described ${ }^{20}$.

Net carbohydrate and lipid oxidations were calculated by using the equations of Livesey \& Elia ${ }^{21}$. Non-oxidative glucose disposal, i.e. mainly glycogen storage, was calculated as the difference between the amount of glucose absorbed and carbohydrate oxidation cumulated over the $6 \mathrm{~h}$ following glucose absorption.

Total rate of plasma glucose appearance (RaT) and disappearance (RdT) following glucose absorption were calculated from the isotopic enrichment in ${ }^{2} \mathrm{H}$ of plasma glucose, by using Steele's equation ${ }^{22}$ as modified by De Bodo et al. ${ }^{23}$. 


\section{Statistical methods}

All results are expressed as means and their standard errors. The comparison between the periods with and without fish oil was made by a two-factor ANOVA with repeated measures and a two-tailed paired Student's $t$ test where appropriate. Differences were regarded as significant when $P<0.05$.

\section{Results}

Fatty acid content of plasma TAG

EPA and DHA content of plasma NEFA and TAG increased significantly after fish oil supplementation (Fig. 1), demonstrating a good compliance of patients for fish oil intake.

Thermogenic response to glucose and plasma catecholamines

Resting EE was not different before and after fish oil supplementation (0.0946 (SEM 0.0029) v. 0.0995 (SEM 0.0598) kJ/kg
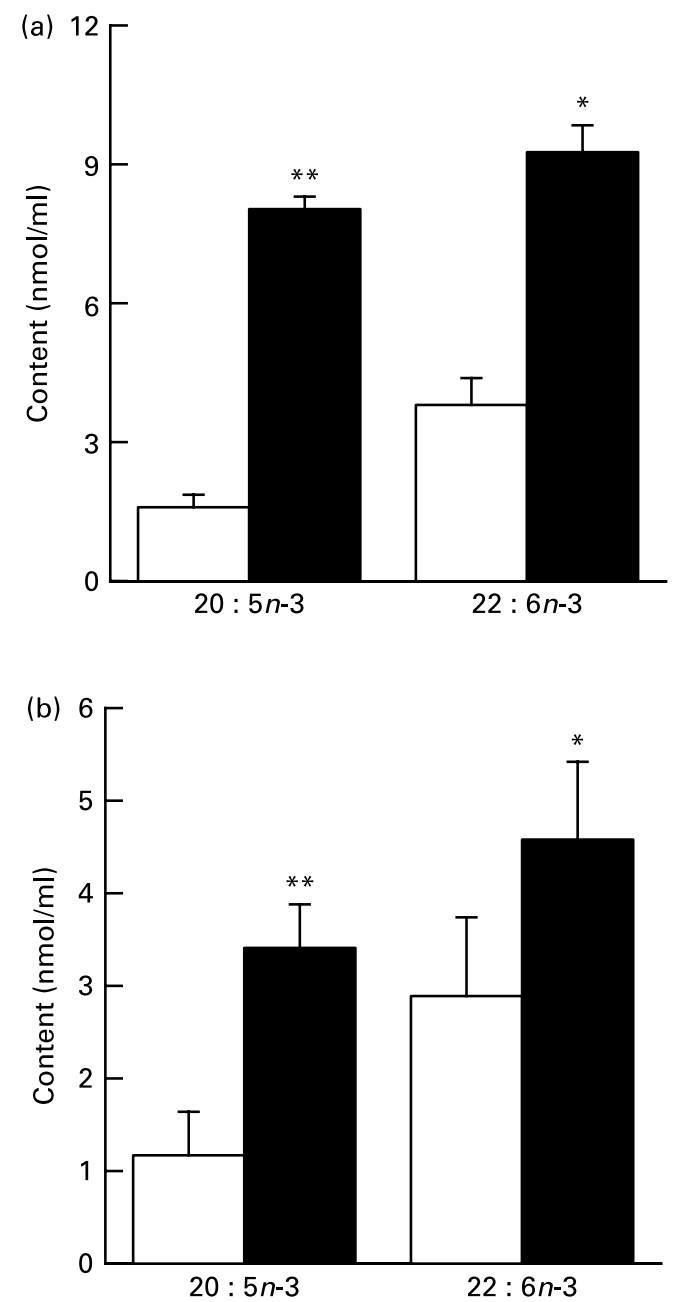

Fig. 1. Content in EPA (20:5n-3) and DHA (22:6n-3) of plasma TAG (a) and NEFA (b) in haemodialysis patients before $(\square)$ and after $(\square)$ an oral 3-week fish oil supplementation. Values are means with their standard errors depicted by vertical bars. Mean values were significantly different from those before supplementation: ${ }^{\star} P<0.05,{ }^{* \star} P<0.01$. fat-free mass per min, respectively (0.0226 (SEM 0.0007) $v$. 0.0238 (SEM 0.0143) $\mathrm{kcal} / \mathrm{kg}$ fat-free mass per min, respectively)). Before fish oil supplementation, EE increased
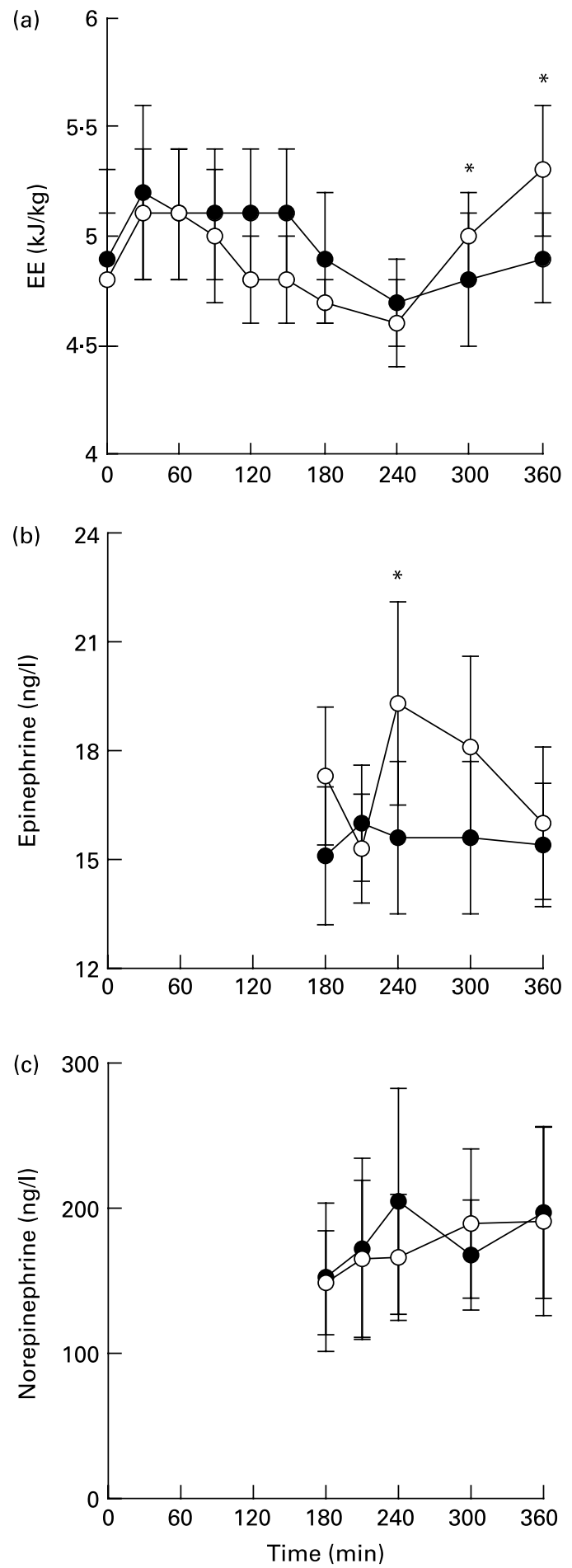

Fig. 2. Thermogenic response (a), and plasma epinephrine (b) and norepinephrine (c) concentrations following a $1 \mathrm{~g} / \mathrm{kg}$ glucose load in haemodialysis patients before $(O)$ and after $(\bullet)$ an oral 3-week fish oil supplementation. Values are means with their standard errors depicted by vertical bars. (a), Mean values were significantly different from those at time $240 \mathrm{~min}$ : ${ }^{\star} P<0.05$. (b, c) Mean values were significantly different from those at time 210 min: ${ }^{*} P<0 \cdot 05$. EE, energy expenditure. 
after glucose oral absorption from time 0 to time $60 \mathrm{~min}$ $(P<0.05)$, decreased from time $60 \mathrm{~min}$ until time $240 \mathrm{~min}$, then re-increased abruptly from time 240 to time $360 \mathrm{~min}$ $(P<0.05)$ (Fig. 2). Plasma catecholamines increased concomitantly to the re-increase in EE (Fig. 2). Five patients displayed symptoms evocative of sympathetic overactivity, i.e. tremulousness, palpitations, anxiety and sweating.

After fish oil, contrarily to what was observed before fish oil, no re-increase in EE was observed from time 240 to time $360 \mathrm{~min}$ (Fig. 2). Contrarily to what was observed before fish oil, plasma epinephrine did not increase from 180 to $240 \mathrm{~min}$ after fish oil (Fig. 2). Plasma norepinephrine after fish oil remained similar to before fish oil supplementation (Fig. 2). Symptoms of sympathetic overactivity remained unchanged in the same five patients after fish oil supplementation.

\section{Substrate oxidation}

Basal carbohydrate oxidation was similar before and after fish oil (1.68 (SEM 0.27) v. 1.66 (SEM 0.19) mg/kg per min, respectively). Basal lipid oxidation was also similar before and after fish oil (0.99 (SEM 0.10) v. 1.19 (SEM 0.10) $\mathrm{mg} / \mathrm{kg}$ per min, respectively). Cumulated carbohydrate and lipid oxidation and non-oxidative glucose disposal were similar before and after fish oil supplementation (Table 2).

\section{Metabolites and insulin}

Basal concentrations of plasma glucose, NEFA and insulin are reported in Table 3 . Kinetics of glycaemia, insulin and NEFA were similar before and after fish oil supplementation (Fig. 3).

\section{Plasma glucose fluxes}

Basal RaT was not different before and after fish oil supplementation (2.14 (SEM) 0.13 v. 2.04 (SEM 0.07) $\mathrm{mg} / \mathrm{kg}$ per min, respectively). Cumulated RaT and RdT were not different before and after fish oil (Table 2).

\section{Discussion}

The main result of the present study is the marked attenuation by fish oil of the adrenergic overactivity induced by oral glucose in the HD patients. The kinetics of thermogenic response to oral glucose before fish oil supplementation was characterized by a re-increase in EE during the last $2 \mathrm{~h}$ of the study. This re-increase in EE coincided with both an increase in plasma catecholamines, mainly epinephrine, and symptoms (in five of the eight patients) evocative of sympathetic overactivity, i.e. tremulousness, palpitations, anxiety and sweating, looking like neurogenic symptoms of hypoglycaemia ${ }^{24}$. Taken together, these present observations strongly suggest a sympathoadrenal activation in the patients in response to oral glucose. This sympathoadrenal activation was likely triggered by the abrupt decrease in glycaemia from time 120 to time $240 \mathrm{~min}$. The fact that the hypoglycaemia threshold was far from being reached strongly reinforces the hypothesis of a sympathoadrenal overactivity in HD patients as previously shown by others ${ }^{5-8}$. These neurogenic symptoms are very unusual during an oral glucose load; they are typically observed only in non-diabetic subjects with reactive hypoglycaemia.

Following fish oil, the re-increase in EE over the last $2 \mathrm{~h}$ of the experiment was completely blunted, in parallel to the blunting of the increase in plasma epinephrine concentrations. As the increase in plasma norepinephrine concentrations remained unaffected by fish oil, the re-increase in EE was very likely specifically linked to adrenergic activation in HD patients. It has been shown in healthy subjects that the facultative thermogenic response to glucose was due to adrenergic activation $^{25}$. The blunting of adrenergic response by fish oil has been previously reported in healthy subjects during mental stress ${ }^{10}$. Whether fish oil blunted the re-increase in EE, it did not prevent the neurogenic symptoms of sympathetic activation. As neurogenic symptoms associated to hypoglycaemia are mainly related to sympathetic activation rather than adrenal activation ${ }^{26}$, on the one hand, and as circulating norepinephrine is derived largely $(9-98 \%)$ from sympathetic postganglionic neurons $\mathrm{s}^{27,28}$, on the other hand, it can be concluded that in the HD patients fish oil attenuated specifically adrenergic overactivity.

Fish oil altered neither glycaemic and insulin responses to oral glucose nor plasma glucose utilization, carbohydrate oxidation and non-oxidative glucose disposal. This contrasts with what has been reported in healthy subjects. Indeed, fish oil decreased by $40 \%$ the insulinaemic response to oral glucose ${ }^{11}$ and partially prevented the excessive increase in insulinaemia induced by a $2 \mathrm{~d}$ dexamethasone treatment ${ }^{12}$. It can be hypothesized that fish oil was ineffective in decreasing insulinaemic response to oral glucose in the HD patients because of a

Table 2. Cumulated substrate oxidation, non-oxidative glucose disposal (NOGD) and plasma glucose fluxes (Mean values with their standard errors)

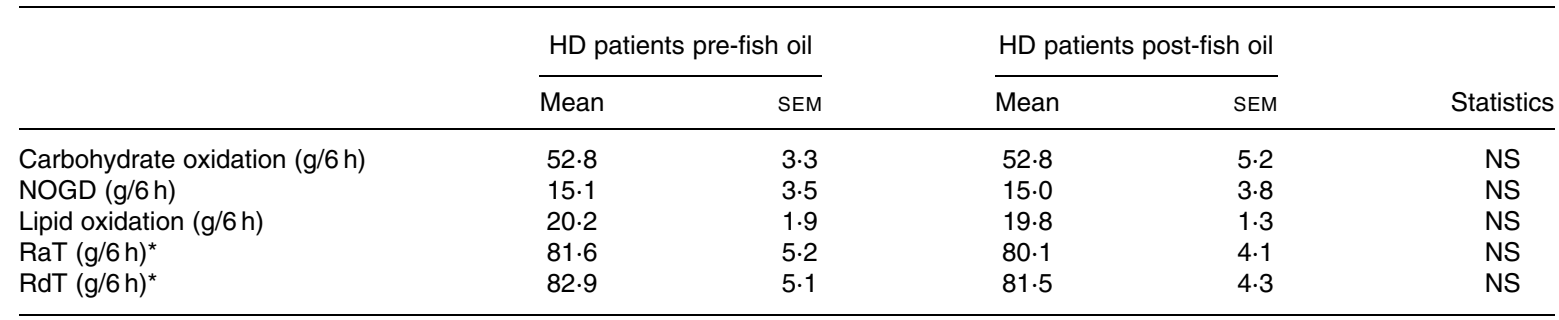

$\mathrm{HD}$, haemodialysis; RaT, total rate of plasma glucose appearance; RdT, total rate of plasma glucose disappearance.

* To obtain in mol/ $/ 6 \mathrm{~h}$, divide by 180 . 
Table 3. Basal concentrations of plasma metabolites and insulin (Mean values with their standard errors)

\begin{tabular}{lccccc} 
& \multicolumn{2}{c}{$\begin{array}{c}\text { HD patients } \\
\text { without fish oil }\end{array}$} & & \multicolumn{2}{c}{$\begin{array}{c}\text { HD patients } \\
\text { with fish oil }\end{array}$} \\
\cline { 2 - 3 } \cline { 5 - 6 } & Mean & SEM & & Mean & SEM \\
\cline { 2 - 3 } Glycaemia $(\mathrm{mm})^{*}$ & $4 \cdot 8$ & $0 \cdot 1$ & & $4 \cdot 7$ & $0 \cdot 2$ \\
Insulinaemia $(p m) \dagger$ & 32 & 4 & & 35 & 4 \\
NEFA $(\mu \mathrm{m})$ & 378 & 54 & & 410 & 92
\end{tabular}

$\mathrm{HD}$, haemodialysis patients.

* To obtain in $\mathrm{g} / \mathrm{l}$ divide by 5.55 .

†To obtain in $\mathrm{mU} / \mathrm{ml}$, divide by 6 .

pre-existing insulin resistance. Indeed, it has been repeatedly shown that fish oil supplementation was unable to reverse insulin resistance in patients with type 2 diabetes (reviews in Delarue et al. ${ }^{29}$ and Lombardo \& Chicco ${ }^{30}$ ). As HD patients generally display insulin resistance ${ }^{9}$, the lack of effect of fish oil could be interpreted as its inability to reverse insulin resistance once installed. Data in rodents also sustain the inability of fish oil to reverse insulin resistance whereas it is able to prevent its installation (reviews in Delarue et al. ${ }^{29}$ and Lombardo \& Chicco $^{30}$ ).

The lack of randomization of fish oil intake in the present study is unlikely to explain its effect on the post-glucose kinetics of EE and plasma epinephrine. A cross-over study would have been an ideal design, but EPA and DHA incorporation into membranes has been reported to be as long as 18 weeks $^{31}$ so that the two experiments would have to be performed at least 18 weeks apart. During such a long period other confounding factors could appear, especially in HD patients. Patients had very similar glycaemia, insulinaemia, substrate oxidation and plasma glucose fluxes in the basal state and after glucose without and with fish oil supplementation. In addition, re-increase in EE during the last part of the oral load appears to be specific to our HD patients inasmuch as it has never been reported before, especially in healthy subjects and in patients undergoing continuous ambulatory peritoneal dialysis (CAPD) that we previously studied using the same methodology ${ }^{11,12,20,32}$. Thus, we are very confident that attenuation by fish oil of adrenergic overactivation was not due to the lack of randomization of its administration. It is to be noted that in contrast to haemodialysed patients from the present study and others, sympathetic activity has been reported to be impaired in patients undergoing CAPD ${ }^{33}$. This could explain why we did not observe any neurogenic symptom previously in CAPD patients absorbing an oral glucose load ${ }^{20,32}$. The mechanisms sustaining a decreased sympathetic activity on CAPD remain unclear. It could be possible that chronic peritoneal glucose administration (glucose being used as an osmotic agent) could have deleterious effects comparable to that observed in patients with diabetes.

Sympathetic overactivity has been repeatedly observed in patients with end-stage renal disease undergoing HD. An increased adrenergic response in everyday life induces at least chronic vasoconstriction leading to hypertension and to endothelial dysfunction leading itself to atherosclerosis. In addition, insulin resistance is a common metabolic disorder in patients with end-stage renal disease, leading to increased cardiovascular risk, predisposing to metabolic syndrome and type 2 diabetes and stimulating $\mathrm{Na}^{+}$renal reabsorption favouring hypertension. Fish oil has many beneficial effects: reduction of cardiovascular risk, reduction of adrenergic overactivity induced by mental stress and prevention of insulin resistance. For all those reasons, fish oil supplementation could be very useful in HD patients. We did not observe
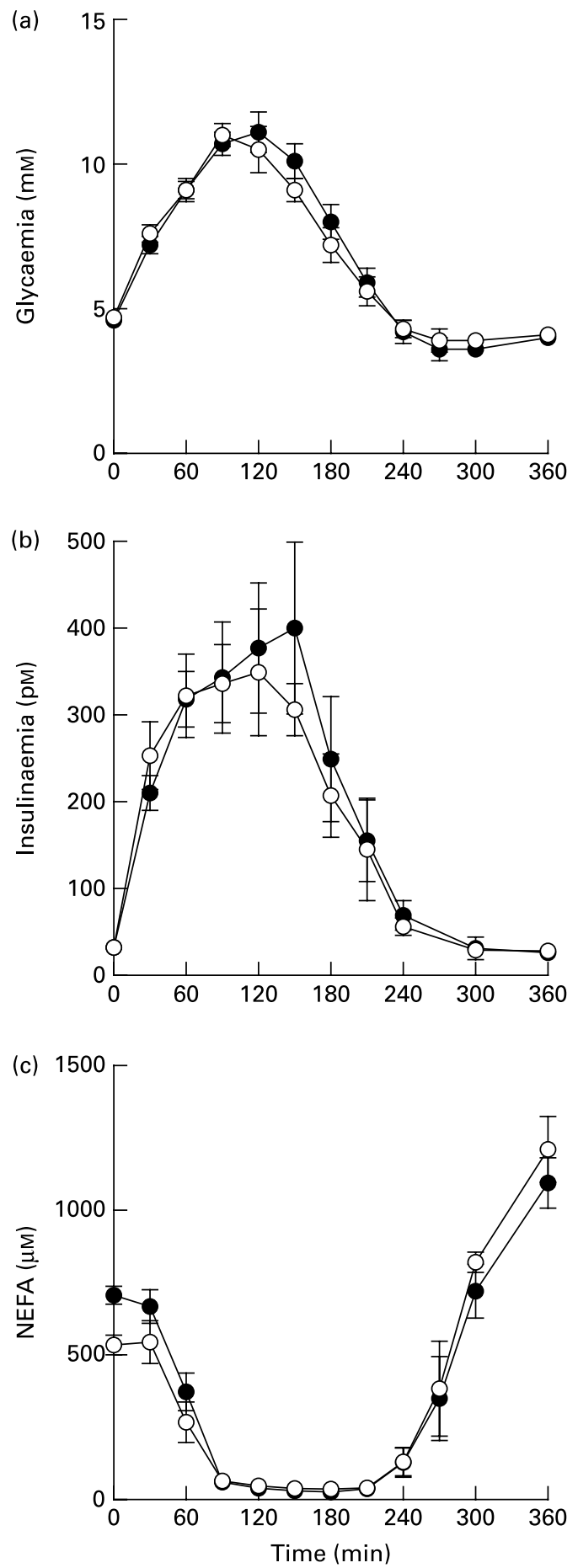

Fig. 3. Plasma glucose (a), insulin (b) and NEFA (c) concentrations in response to a $1 \mathrm{~g} / \mathrm{kg}$ glucose load in haemodialysis patients before $(\bullet)$ and after $(\bigcirc)$ an oral 3 -week fish oil supplementation. Values are means with their standard errors depicted by vertical bars. 
any effect on insulin sensitivity and others did not observe any effect on heart rate variability ${ }^{34}$, suggesting that fish oil is not able to correct all metabolic alterations in HD patients, but the decreased sympathetic overactivity is of potential major interest to reduce vasoconstriction, risk of hypertension and endothelial dysfunction and in longer term to reduce cardiovascular risk. Of course, further studies are needed to confirm in HD patients these possible beneficial long-term effects.

In conclusion, a fish oil supplementation containing EPA + DHA at $1.8 \mathrm{~g} / \mathrm{d}$ over 3 weeks attenuates adrenergic overactivity in response to oral glucose in HD patients without altering whole-body glucose metabolism and insulin sensitivity.

\section{Acknowledgements}

The technical help of Mrs Yvette Creff and Véronique Troadec was deeply appreciated. We thank Mr M. Desage from Centre de Recherche en Nutrition Humaine de Lyon for performing the analysis of isotopic enrichment in ${ }^{2} \mathrm{H}$ of plasma glucose, Mrs M. P. Moineau (Service de Médecine Nucléaire, CHU de Brest) for performing the assays of plasma insulin and Mr J. M. Cottet-Emard (Centre de Biologie Nord, Hôpital de la Croix-Rousse, Lyon) for performing the assays of plasma catecholamines. This work was supported by a grant from the Association d'Aide aux Urémiques de Bretagne and from Region Bretagne.

\section{References}

1. Friedman AN, Moe SM, Perkins SM, Li Y \& Watkins BA (2006) Fish consumption and omega-3 fatty acid status and determinants in long-term hemodialysis. Am J Kidney Dis 47, 1064-1071.

2. Kutner NG, Clow PW, Zhang R \& Aviles X (2002) Association of fish intake and survival in a cohort of incident dialysis patients. Am J Kidney Dis 39, 1018-1024.

3. Sarnak MJ, Levey AS, Schoolwerth AC, et al. (2003) Heart Association Councils on Kidney in Cardiovascular Disease, High Blood Pressure Research, Clinical Cardiology, and Epidemiology and Prevention. Kidney disease as a risk factor for development of cardiovascular disease: a statement from the American Heart Association Councils on Kidney in Cardiovascular Disease, High Blood Pressure Research, Clinical Cardiology, and Epidemiology and Prevention. Circulation 108, 2154-2169.

4. Luke RG (1998) Chronic renal failure - a vasculopathic state. $N$ Engl J Med 339, 841-843.

5. Zoccali C, Mallamaci F, Parlongo S, et al. (2002) Plasma norepinephrine predicts survival and incident cardiovascular events in patients with end-stage renal disease. Circulation 105, 1354-1359.

6. Hausberg M, Kosch M, Harmelink P, Barenbrock M, Hohage H, Kisters K, Dietl KH \& Rahn KH (2002) Sympathetic nerve activity in end-stage renal disease. Circulation 106, 1974-1979.

7. Klein IH, Ligtenberg G, Neumann J, Oey PL, Koomans HA \& Blankestijn PJ (2003) Sympathetic nerve activity is inappropriately increased in chronic renal disease. J Am Soc Nephrol 14, $3239-3244$

8. Kotanko P (2006) Cause and consequences of sympathetic hyperactivity in chronic kidney disease. Blood Purif 24, 95-99.

9. Rigalleau V \& Gin H (2005) Carbohydrate metabolism in uraemia. Curr Opin Clin Nutr Metab Care 8, 463-469.
10. Delarue J, Matzinger O, Binnert C, Schneiter P, Chiolero R \& Tappy L (2003) Fish oil prevents the adrenal activation elicited by mental stress in healthy men. Diabetes Metab 29, 289-295.

11. Delarue J, Couet $\mathrm{C}$, Cohen R, Brechot JF, Antoine JM \& Lamisse F (1996) Effects of fish oil on metabolic responses to oral fructose and glucose loads in healthy humans. Am J Physiol 270, E353-E362.

12. Delarue J, Chang-Hong L, Cohen R, Corporeau C \& Simon B (2006) Interaction of fish oil and a glucocorticoid on metabolic responses to an oral glucose load in healthy human subjects. Br J Nutr 95, 267-272.

13. Acheson K, Jequier E \& Wahren J (1983) Influence of betaadrenergic blockade on glucose-induced thermogenesis in man. J Clin Invest 72, 981-986.

14. Acheson KJ, Ravussin E, Wahren J \& Jequier E (1984) Thermic effect of glucose in man. Obligatory and facultative thermogenesis. J Clin Invest 74, 1572-1580.

15. Matsuda M \& DeFronzo RA (1999) Insulin sensitivity indices obtained from oral glucose tolerance testing: comparison with the euglycemic insulin clamp. Diabetes Care 22, 1462-1470.

16. Folch J, Lees M \& Sloane Stanley GH (1957) A simple method for the isolation and purification of total lipides from animal tissues. J Biol Chem 226, 497-509.

17. Marty Y, Delaunay F, Moal J \& Samain JF (1992) Changes in the fatty acid composition of the scallop Pecten maximus (1.) during larval development. J Exp Mar Biol Ecol 163, 221-234.

18. Soudant P, Chu FLE \& Marty Y (2000) Lipid class composition of the protozoan Perkinsus marinus an oyster parasite, and its metabolism of a fluorescent phosphatidylcholine analog. Lipids 35, 1387-1395.

19. Jequier E, Acheson K \& Schutz Y (1987) Assessment of energy expenditure and fuel utilization in man. Anпu Rev Nutr 7, 187-208.

20. Delarue J, Maingourd C, Lamisse F, Garrigue MA, Bagros P \& Couet C (1994) Glucose oxidation after a peritoneal and an oral glucose load in dialyzed patients. Kidney Int 45, 1147-1152.

21. Livesey G \& Elia M (1988) Estimation of energy expenditure, net carbohydrate utilization, and net fat oxidation and synthesis by indirect calorimetry: evaluation of errors with special reference to the detailed composition of fuels. Am J Clin Nutr 47, $608-628$.

22. Steele R, Wall JS, De Bodo RC \& Altszuler N (1956) Measurement of size and turn over rate of body glucose pool by the isotope dilution method. Am J Physiol Endocrinol Metab 187, E15-E24.

23. De Bodo RC, Steele R, Altszuler N, Dunn A \& Bishop JS (1963) On the hormonal regulation of carbohydrate metabolism: studies with ${ }^{14} \mathrm{C}$ glucose. Recent Prog Horm Res 19, 445-448.

24. Cryer PE (1999) Symptoms of hypoglycemia, thresholds for their occurrence, and hypoglycemia unawareness. Endocrinol Metab Clin North Am 28, 495-500.

25. Muller MJ, Acheson KJ, Piolino V, Jeanpretre N, Burger AG \& Jequier E (1992) Thermic effect of epinephrine: a role for endogenous insulin. Metabolism 4, 582-587.

26. DeRosa MA \& Cryer PE (2004) Hypoglycemia and the sympathoadrenal system: neurogenic symptoms are largely the result of sympathetic neural, rather than adrenomedullary, activation. Am J Physiol Endocrinol Metab 287, E32-E41.

27. Brown MJ, Jenner DA, Allison DJ \& Dollery CT (1981) Variations in individual organ release of noradrenaline measured by an improved radioenzymatic technique: limitations of peripheral venous measurements in the assessment of sympathetic nervous activity. Clin Sci (Colch) 61, 585-590.

28. Hoeldtke RD, Cilmi KM, Reichard GA Jr, Boden G \& Owen OE (1983) Assessment of norepinephrine secretion and production. J Lab Clin Med 101, 772-782. 
29. Delarue J, LeFoll C, Corporeau C \& Lucas D (2004) N-3 long chain polyunsaturated fatty acids: a nutritional tool to prevent insulin resistance associated to type 2 diabetes and obesity? Reprod Nutr Dev 44, 289-299.

30. Lombardo YB \& Chicco AG (2006) Effects of dietary polyunsaturated $n-3$ fatty acids on dyslipidemia and insulin resistance in rodents and humans. J Nutr Biochem 17, 1-13.

31. Endres S, Ghorbani R, Kelley VE, et al. (1989) The effect of dietary supplementation with $n-3$ polyunsaturated fatty acids on the synthesis of interleukin-1 and tumor necrosis factor by mononuclear cells. $N$ Engl J Med 320, 265-271.
32. Delarue J, Maingourd C, Couet C, Vidal S, Bagros P \& Lamisse F (1998) Effects of oral glucose on intermediary metabolism in continuous ambulatory peritoneal dialysis patients versus healthy subjects. Perit Dial Int 18, 505-511.

33. Jassal SV, Allen JA, Douglas JF \& Stout RW (1998) Autonomic function in patients on continuous ambulatory peritoneal dialysis. Perit Dial Int 18, 46-51.

34. Svensson M, Schmidt EB, Jorgensen KA \& Christensen JH (2007) The effect of n-3 fatty acids on heart rate variability in patients treated with chronic hemodialysis. J Ren Nutr 17, $243-249$. 